\title{
THE INFLUENCE OF CAUSAL EXPLANATIONS AND DIAGNOSTIC LABELING ON PSYCHOLOGY STUDENTS' BELIEFS ABOUT TREATMENTS, PROGNOSIS, DANGEROUSNESS AND UNPREDICTABILITY IN SCHIZOPHRENIA.
}

MAGLIANO, L., READ, J., RINALDI, A., COSTANZO, R., DE LEO, R., SCHIOPPA, G., PETRILLO, M., ZACCARO, A., CAMPITIELLO, F. (2015). The influence of causal explanations and diagnostic labelling on psychology students' beliefs about treatments, prognosis, dangerousness and unpredictability in schizophrenia. Community Mental Health Journal, 52(3):361-9.

doi: 10.1007/s10597-015-9901-5

\section{ABSTRACT}

This study explored views of 566 Italian psychology students about schizophrenia. The most frequently cited causes were psychological traumas (68\%) and heredity (54\%). Thirty-three percent of students firmly believed that people with the condition could recover. Reporting heredity among the causes, and identifying schizophrenia were both associated with prognostic pessimism, greater confidence in pharmacological treatments and lower confidence in psychological treatments. Schizophrenia labeling was also associated with higher perception of unpredictability and dangerousness. Compared to first year students, fourth/fifth year students more frequently reported heredity among the causes, and were more pessimistic about schizophrenia recovery. Stigma topics should be included in future psychologists' education.

KEY-WORDS: stigma; schizophrenia; psychology students; causal explanations; diagnostic labeling 
The INFLUENCE OF CAUSAL EXPLANATIONS AND DIAGNOSTIC LABELING ON PSYCHOLOGY STUDENTS' BELIEFS ABOUT TREATMENTS, PROGNOSIS, DANGEROUSNESS AND UNPREDICTABILITY IN SCHIZOPHRENIA.

\section{INTRODUCTION}

Despite the strong evidence-base that adverse life events, especially childhood traumas, increase the probability of developing schizophrenia later in life (Matheson et al. 2012; Read et al. 2013a, b), and the existence of effective non-pharmacological treatments for this disorder, People with Schizophrenia (PWS) rarely receive the psychological support they need. Among the psychological treatments whose efficacy in schizophrenia have been repeatedly proved, are cognitive therapy and family psychoeducation. Cognitive therapy for psychosis is a treatment aimed at reducing the distress experienced by PWS and improving their quality of life. The purpose of this therapy is not necessarily to reduce the frequency of psychotic symptoms but, rather, to help patients to achieve their own specific goals in relation to problems that they have identified themselves (Morrison 2013). In particular, this treatment is focused on generating less distressing explanations for psychotic experiences rather than attempting to eliminate these experiences. An increasing body of evidence supports the efficacy of cognitive therapy in schizophrenia relative to routine care and treatment-as-usual (Morrison et al. 2013; 2014). Metaanalyses have concluded that cognitive-behavioral approaches are effective in schizophrenia and should be routinely offered to persons with this disorder (Sarin et al. 2011). Although cognitive therapy is now recommended by several guidelines for the treatment of schizophrenia (Dixon 2010; Gaebel et al. 2005; NICE 2014), its availability remains poor. For instance, a study on 187 randomly selected PWS in contact with mental health services in North-West England (Haddock et al. 2014) found that only ten received cognitive therapy, and only three of these service users, and two of their families, received family interventions within the 12-month audit period. Another study, of 19 Italian Mental Health Services (MHS) comparing routine practices and the evidence-based NICE guidelines to promote recovery in schizophrenia (Semisa et al. 2008) found that in $60 \%$ of MHS no PWS received even three sessions of cognitive therapy per year, while in $40 \%$ of MHS less than $10 \%$ of PWS received this psychological treatment. As far as family psychoeducation is concerned, the efficacy of this cognitive-behavioral approach - aimed at educating PWS and their relatives about this disorder and improving their communication and problem solving skills - has been demonstrated by more than 50 RCTs and meta-analyses (Pharoah et al. 2010). In particular, family psychoeducation has found to have positive impact on the recovery of PWS, with a significant reduction of relapse rates, and improvement in social functioning. Although family support is recommended by many guidelines for treatment of schizophrenia (Gaebel et al. 2005; 
NICE 2014), it is rarely available for PWS and their relatives (Dixon et al. 2010; Prytis et al. 2011). Data from the above-mentioned Italian study (Semisa et al. 2008) reported that in $45.5 \%$ of the MHS, family psychoeducation was available for less than $10 \%$ of families. Another study on a 30 randomly selected Italian MHS showed that only $8 \%$ of families of PWS received psycho-educational support (reported in Magliano et al. 2006). Other approaches with some empirical support include supportive psychodynamic therapy (reported in Summers \& Rosenbaum 2013) and Open Dialogue (Seikkula et al. 2003).

The lack of psychological therapies for PWS is due to many variables, including the relative recency of evidence-based psychological treatments for psychosis compared to antipsychotic medication, and the poor availability of training opportunities for psychologists (Buck et al. 2014). Semisa et al. (2008) found that less than $10 \%$ of psychologists were skilled in cognitive-behavioral approaches for psychosis in $63.6 \%$ of MHSs, and less than $10 \%$ of psychologists were trained in family cognitive-behavioral therapy in $45.5 \%$ of MHSs.

Among the barriers that inhibit non-pharmacological interventions, are negative attitudes of health professionals towards PWS. Studies on this topic report that health professionals share the prejudices of the general public (Kvale et al. 2013; Magliano et al. 2004; Pescosolido et al. 2010; Read \& Harre 2001; Read et al. 2013b; Speerfock et al. 2014) including beliefs that PWS are dangerous, unpredictable, and affected by an incurable illness whose symptoms are socially and psychologically meaningless and out of the person's control (Nordt et al. 2006; Deacon 2013; Reavley et al. 2014).

Results from the few studies specifically exploring the attitudes of psychologists towards persons with mental illness suggest that psychologists tend to have more positive attitudes, including a more optimistic view of outcome, compared to some other professional groups (as cited in Servais and Sauders 2007). A recent study exploring the attitudes of health professionals toward persons diagnosed with either depression, schizophrenia, post-traumatic stress disorder, or social phobia (Reavley et al. 2014), found that psychologists were less likely to hold stigmatizing attitudes or desire of social distance than general practitioners and psychiatrists. However, there is also evidence that psychologists are less willing to interact with PWS than with persons with other mental problems such as depression, tend to distance themselves from PWS, and view these people as considerably more ineffective and incomprehensible than individuals with other mental problems (Servais \& Saunders 2007; Reavley et al. 2014; Buck et al. 2014). These views of PWS may further discourage the efforts of people with this diagnosis to engage with health professionals.

As future health professionals, medical students and psychology students constitute crucial target populations for improving quality of care for PWS. Studies of medical students attitudes toward PWS reported 
that $71-89 \%$ of them believe that persons with this disorder are unpredictable, $26-78 \%$ are convinced that they are dangerous, and $4-21 \%$ view these people as affected by an incurable disorder (as cited in Magliano et al. 2012, 2013). Research has also found that medical students who label a case as schizophrenia and those who attribute this disorder to genetic factors perceive higher social distance from PWS (Magliano et al. 2012). However, medical students who interpret schizophrenia within a bio-psycho-social model express lower social distance toward persons with this disorder, are more optimistic about recovery, and include psychologists as recommended professionals (Magliano et al. 2013). Research also reveals that medical students tend to adhere to a biogenetic model of schizophrenia, particularly in the late stage of their medical training, and that the acquisition of psychiatric skills has limited effects on their attitudes towards PWS, including prognostic pessimism (as cited in Magliano et al. 2012, 2013). A study of second- and sixth-year students from three Turkish faculties of Medicine (Ay et al. 2006) found that final-year students were more likely to label a case-vignette 'schizophrenia' ( $86 \%$ vs. $12 \%$ ) and had a higher confidence level in drug treatments for the illness. However, the percentage of students who believed that these persons were dangerous increased from $26 \%$ of the secondyear students to $39 \%$ of the sixth-year students, and the percentage of students that viewed schizophrenia as an incurable illness increased from $12 \%$ to $32 \%$. Another study, on 381 Italian medical students (Magliano et al. 2013), found that, compared to first-year students, fifth/sixth-year students more frequently mentioned heredity (35\% vs. $81 \%$ ) and stress ( $45 \%$ vs. $69 \%$ ) among the causes of schizophrenia (Magliano et al. 2012), more strongly endorsed drugs as effective treatments ("completely true" $14 \%$ vs. $51 \%$ ), and had less confidence in psychologists (53\% vs. $36 \%)$.

Compared to the large amount of research on medical students' views of schizophrenia at different stages of their training, only few findings are available on attitudes of future psychologists towards PWS. A study of 469 New Zealand psychology students found that the majority believed that mental patients (without referring to specific diagnosis) are unpredictable, antisocial and dangerous (Read and Harrè 2001). Furthermore, the students who reported biological or genetic factors among the causes of mental illness had more negative attitudes towards mental patients. In experimental settings, a number of studies showed that negative attitudes towards PWS can be improved in students through ad-hoc educational interventions. Lincoln et al. (2008) examined the impact of different educational interventions on the etiology of schizophrenia and on stigmatizing attitudes in 60 medical students and 61 psychology students. These authors reported that at baseline, before the experimental intervention, there were no significant differences in the mean stereotype scores (including beliefs about dangerousness, responsibility, unpredictability/incompetence, and poor prognosis in schizophrenia) 
between the medical students and the psychology students. Moreover both groups had higher levels of negative stereotypes for schizophrenia than for depression. However, psychology students revealed more desire for social distance from PWS than medical students. The study also documented that medical students who favored biogenetic explanations over psychosocial ones reported less attribution of responsibility, whereas psychology students who favored biogenetic explanations over psychosocial ones reported more pessimism about prognosis. Finally, the study found that a biogenetic-oriented intervention reduced a sense of blame toward PWS, while increased prognostic pessimism in psychology students and weakened perception of PWS as unpredictable/incompetent among medical students. Taking into account findings reported above, results from studies on medical students views of schizophrenia are only partially generalizable to future psychologists. A study on 126 psychology students in New Zealand (Read \& Law 1999) found that a series of lectures presenting the psychosocial causes of severe mental health problems, including for people diagnosed with schizophrenia, reduced students' perceptions of mental patients as dangerous and unpredictable. At baseline, this study documented non-significant trends for endogeneous (biogenetic) causal beliefs to be related to perceived dangerousness and unpredictability and negative behavioural intentions (desire for social distance) among psychology students. Another study on the impact of an educational intervention on schizophrenia, including personal experiences and scientific evidences about recovery and perceived dangerousness in schizophrenia, provided to 211 medical and psychology students' views of this disorder (Magliano et al. 2014) found that, at baseline assessment, heredity was the most frequently cited cause of schizophrenia, and only $29 \%$ of students believed that PWS could recover. At immediate post-intervention reassessment, the percentage of students who firmly believed that PWS could recover increased to $84 \%$.

In this paper, we report data on causal explanations and other beliefs about schizophrenia in 566 Italian psychology students, of which 235 were in their first year of general Psychology course, and 331 were in their fourth or fifth year of Psychology training. To our knowledge, this is the first study comparing psychology students at different stages of their studies, and the first study of psychology students' views to be carried out in Italy. Data were collected using the same questionnaire adopted in previous studies on medical students, in order to facilitate comparisons among students from different health disciplines (not examined in this paper).

Taking into account the above-mentioned literature data on views of schizophrenia in future health professionals, this study aimed to test whether psychology students' views of schizophrenia would:

a) be influenced by diagnostic labeling and causal explanations. We expected that, compared to students who did not, those who identified schizophrenia in a clinical description, and those who reported heredity among 
its causes would be: (i) more pessimistic about the possibility that PWS could recover; (ii) more convinced of the usefulness of drug treatments and less convinced of the usefulness of psychosocial treatments; (iii) less likely to recommend a psychologist; and (iv) more likely to believe that people with schizophrenia were dangerous and unpredictable;

b) differ from early to late stages of psychology education. We expected that - as suggested by findings from previous studies reported above - Psychology students in their fourth or fifth year of training, compared to those in their first year, would (i) assign more relevance to biological factors in the development of schizophrenia, (ii) be more convinced of the usefulness of drug treatments and less convinced of the usefulness of psychosocial treatments, (iii) be less likely to recommend a psychologist, (iv) be more pessimistic about recovery; and v) be more likely that PWS were dangerous and unpredictable.

\section{METHODS}

\section{Participants and Procedure}

Participants were undergraduate students who attended their psychology training at the Second University of Naples, Italy. Of the 567 psychology students who were contacted, all agreed to participate in the study. One case was excluded because of incomplete responses. Of the 566 students, 235 were taking their first year of general Psychology course, and 331 were in their first or second year of a Master Degree in Clinical Psychology or in Psychology applied to Institutional Contexts (corresponding to fourth or fifth year of Psychology training). The mean age of the sample was 23.0 (SD 4.2) years, and 477 (84.9\%) students were female. The Master Degree in Psychology applied to Institutional Contexts provides students with psychology skills to work in institutional settings, mainly in the sectors of justice, education, public health services, and companies. It also provides students with basic psycho-therapy competences to be further developed in post degree training. All students receive basic education in mental health problems at the third year of general Psychology course, and advanced education in mental health problems at the second year of both Master Degrees. In Italy, $87 \%$ of graduate students in general Psychology attend a Master Degree in psychology (Consorzio Interuniversitario Alma Laurea, 2014). Therefore, most first year students assessed in the study are expected to attend a Master Degree in Psychology in their future and to become registered/clinical psychologists. In order to be registered as Psychologists, after completing a Master Degree course psychology students have to attend a mandatory 1-year postgraduate practical training in credited institutions (such as Mental Health Departments, General Hospitals, Schools, Work Companies, and Courts), and pass a final exam. During 1-year postgraduate practical training, students may have contacts with 
PWS, if they choose to attend Mental Health Departments. 80\% of registered Psychologists work as psychologists. Of these, $44 \%$ worked in public institutions and $56 \%$ is engaged in clinical activities (Bosio \& Lozza, 2008). In Mental Health Departments, psychologists may work with PWS mainly in community centers and day-centers for rehabilitation.

The survey was carried out from March 2012 to March 2013. Students were contacted in classroom at the end of lessons and invited to participate on a voluntary basis. Consent was sought by providing eligible participants with written information on the survey. Students who accepted to take part in the study were asked to fill in QO anonymously.

The study was conducted in accordance with the academic rules of the SUN, with the Head of the Faculty of Psychology, and with approval from the local Research Ethical Board.

The authors declare that they have no known conflicts of interest, and certify their responsibility for the manuscript.

\section{Measures}

Data were collected by using the Opinions on mental illness Questionnaire (QO; Magliano et al. 2004), a self-reported tool designed to explore respondent's views of schizophrenia. QO was also used in previous research on views on schizophrenia among medical students at the same University (Magliano et al. 2013; 2014). This tool contains a clinical description of schizophrenia according to ICD-10 criteria (without naming the diagnosis), followed by a list of items exploring respondent's beliefs about: a) the causes of schizophrenia (12 items); b) the effectiveness of available treatments for schizophrenia and the right of PWS to be informed on their condition and drugs treatments (7 items); c) the psychosocial consequences of the condition (i.e., problems that PWS may experience in family and affective relationships, and in social and occupational roles; social distance from and perception of recognizability, dangerousness and unpredictability of persons with the disorder - 21 items). Four additional items explored respondents' belief about which professionals should be involved in the care of PWS. Respondents were invited to read the clinical description of schizophrenia (reported in Appendix A) and to complete the questionnaire, thinking about "People with a Condition like that reported in the description (PWC)", and suggesting the diagnosis.

Respondents' beliefs about causes and appropriate professionals were assessed by "yes/no" items, while beliefs about b-c variables were rated on a 3-point scales, from $1=$ "not true" to $3=$ "completely true". OQ psychometric properties have been previously tested (Cohen's kappa ranging from 0.50 and 1 for $74 \%$ of the items; 
subscales' Cronbach's alpha ranging between .42 and .72; Magliano et al. 2004). Subscales' Cronbach's alpha measured in the study sample ranged from .32 to .77 . In this study, we used items exploring beliefs about causes of schizophrenia, and on possibility of recovery, effectiveness of drugs and of psychological treatments, type of professionals, and respondents' perception of dangerousness and unpredictability of PWC.

\section{Data analysis}

Chi squares $\left(\chi^{2}\right)$ were used to examine the associations of causal explanations with diagnostic labelling, and of causal explanations and diagnostic labelling with respondents' beliefs about: a) professionals to be involved in the treatment of a PWC; b-c) usefulness of drugs and of psychological treatments; d) recovery; and, e-f) dangerousness and unpredictability in the disorder. The same test was used to explore differences between firstyear and fourth/fifth-year students in causal explanations and beliefs about a to $\mathrm{f}$ variables. The Statistical significance level was set at $p<.05$, with Bonferroni correction.

\section{RESULTS}

\section{Descriptive results}

Psychological traumas was the most frequently cited cause of the condition, followed by heredity and stress (Table 1). Thirty-three percent of the students completely agreed with the statement "PWC can recover". Sixtyone percent of the respondents completely believed that psychological interventions were useful in the treatment of the disorder; while $23.7 \%$ were totally convinced of the usefulness of drugs (Table 2). The psychologist was recommended among the treating professionals by $79.3 \%$ of students, and medical doctor by $85.8 \%$ of them (psychiatrist (77.4\%), neurologist (29.7\%), and GP (2.8\%)). Twelve percent completely agreed with the statement "PWC are dangerous to others", while $41.5 \%$ were totally convinced that "PWC are unpredictable" .

Sixty-three percent labeled the described condition as schizophrenia, 17.5\% as depression, and 3.2\% as anxiety. Furthermore, $9.2 \%$ of participants named the condition as nervous breakdown, $3.2 \%$ as mental illness, and $1.9 \%$ as psychological problems, while $1.9 \%$ of participants did not know how, or chose not, to label the condition.

\section{Associations of diagnostic labeling with causal explanations, and with students' beliefs about the disorder}


Participants who identified schizophrenia, compared to those who did not, were more likely to endorse heredity $\left(\chi^{2}=150.6, d f 1, p<.05\right)$, and chemical imbalance $\left(\chi^{2}=35.9, d f 1, p<.05\right)$, and less likely to mention stress $\left(\chi^{2}=56.4, d f 1, p<.05\right)$, and family conflicts $\left(\chi^{2}=28.3 d f 1, p<.05\right)$ among the causes of the disorder (Table 1$)$. Furthermore, students who identified schizophrenia more frequently recommended medical doctor among the treating professionals compared to those who did not label the case as schizophrenia $\left(95.4 \%\right.$ vs. $69.4 \%, \chi^{2}=71.7$, $d f 1, p<.05)$.

Students who labeled the condition schizophrenia were more skeptical about recovery $\left(\chi^{2}=33.1, d f 2, p<.05\right)$ and about the usefulness of psychological treatments $\left(\chi^{2}=16.3, d f 2, p<.05\right)$, and were more confident about drugs $\left(\chi^{2}=56.2, d f 2, p<.05 ;\right.$ Table 2). Furthermore, these students perceived PWC as more unpredictable and dangerous $\left(\chi^{2}=16.1\right.$, df $2, \mathrm{p}<.05 ; \chi^{2}=20.3$, df $\left.1, \mathrm{p}<.05\right)$, than students who did not label the case as schizophrenia.

\section{Associations of causal explanations with students' beliefs about the disorder}

Students who reported heredity among the causes were, compared to those who did not, more pessimistic about recovery ("completely true": $18.0 \%$ vs. $48.3 \%, \chi^{2}=52.0, d f 2, p<.05$ ), more likely to be completely sure about the usefulness of drug treatments $\left(31.6 \%\right.$ vs. $\left.13.5 \%, \chi^{2}=43.8, d f 2, p<.05\right)$, and more skeptical regarding the usefulness of psychological treatments $\left(50.9 \%\right.$ vs. $\left.72.9 \%, \chi^{2}=29.7, d f 2, p<.05\right)$. Conversely, students who mentioned stress among the causes of the disorder more frequently agreed with the statement "PWC can recover" $\left(41.8 \%\right.$ vs. $\left.24.3 \%, \chi^{2}=18.0, d f 2, p<.05\right)$, and students who reported family conflicts were more skeptical about the usefulness of drug treatments in the treatment of PWC (14.4\% vs. $\left.29.5 \%, \chi^{2}=22.8, d f 2, p<.05\right)$. Finally, students who reported heredity and chemical imbalance among the causes more frequently mentioned medical doctors as appropriate professionals (95.6\% vs. $74.3 \%, \chi^{2}=51.4, d f 1, p<.05 ; 81.1 \%$ vs. 94.7\%, $\chi^{2}=19.0, d f 1$, $p<.05)$

Differences between first and fourth/fifth year students in causal explanations and beliefs about the disorders

Compared to first-year students, fourth/fifth-year students more frequently labeled the description as schizophrenia $\left(1^{\text {st }}\right.$ year: $36.2 \%$ vs. $4^{\text {th }} / 5^{\text {th }}$ year: $\left.82.2 \%, \cdot \chi^{2}=125.0, d f 1, p<.05\right)$. Fourth/fifth-year students more frequently reported heredity ( $1^{\text {st }}$ year: $22.6 \%$ vs $4^{\text {th }} / 5^{\text {th }}$ year: $75.8 \%$ vs. $\left.\chi^{2}=156.9, d f 1, p<.05\right)$, chemical imbalance 
$\left(26.0 \%\right.$ vs. $\left.40.2 \%, \chi^{2}=12.3, d f 1, p<.05\right)$, and use of alcohol $\left(16.6 \%\right.$ vs. $\left.32.3 \%, \chi^{2}=17.8, d f 1, p<.05\right)$, and less mentioned frequenting bad companies among the causes of the disorders $\left(8.9 \%\right.$ vs. $\left.1.5 \%, \chi^{2}=17.3, d f 1, \mathrm{p}<.05\right)$. Fourth/fifth-year students were more skeptical about the possibility that persons with this disorder could be well again ("completely true": $48.8 \%$ vs. $21.4 \%, \chi^{2}=40.5, d f 1, p<.05$ ), and about the usefulness of psychological treatments ("completely true": $69.4 \%$ vs. $54.7 \%, \chi^{2}=12.3, d f 1, p<.05$ ). Conversely, fourth/fifth year students more frequently believed that drugs were useful in the treatments of this disorder ("completely true": $13.6 \%$ vs. $29.8 \%$, $\left.\chi^{2}=32.1, d f 1, p<.05\right)$, and recommended a medical doctor as treating professionals $\left(75.0 \%\right.$ vs. $93.3 \%, \chi^{2}=36.7, d f$ $1, p<.05)$.

\section{DISCUSSION}

The results of this study suggest that future psychologists do understand the role of psychosocial factors in the development of schizophrenia but also that some are not fully aware of the effectiveness of nonpharmacological treatments (Magliano et al. 2006; Dixon et al. 2010; Morrison 2013). Despite 68.2\% of students reporting psychological traumas among the causes of the disorders, and $79.3 \%$ mentioning the psychologist as an appropriate professional, only $60.8 \%$ of students were completely convinced that psychological interventions are useful in the treatment of schizophrenia.

The present findings are consistent with the body of research documenting that a biomedical understanding of medical disorders can have negative effects on attitudes (Angermeyer et al. 2011; Deacon 2013; Pescosolido et al. 2010; Read et al. 2013a, b; Speerforck et al. 2014). Students who reported heredity among the causes were more pessimistic about recovery and were more sceptical about the usefulness of psychosocial treatments in schizophrenia. Furthermore, students who reported biogenetic factors more frequently recommended a medical doctor among the treating professionals. These results support numerous previous findings that the adoption of a biogenetic model of schizophrenia can increase prejudices about incurability of schizophrenia (Angermeyer et al. 2011; Read et al. 2013b; Kvaale et al. 2013) and may led to clinical management of this disorder focused on longterm drug treatments only (Hutton et al. 2013). In particular, a review of 17 experimental studies (reviewed by Read et al., 2013a) produced 20 significant findings about causal beliefs and attitudes toward PWS. In five of the seven findings about bio-genetic beliefs, they made attitudes worse. In all 13 cases, psychosocial beliefs improved attitudes. A study by Bennett et al., (2008) on student in Wales, reported that they were more likely to perceive a person described in a schizophrenia vignette as dangerous and affected by an incurable illness, if the person's condition was explained by genetic causes than by a recent bereavement. Finally, a review by Schomerus et al. 
(2012) reported a trend toward a more biologically-oriented model of mental disorders and a parallel increment of negative attitudes toward PWS among lay people.

Students who identified schizophrenia more frequently mentioned heredity and chemical imbalance as causal factors, and less frequently reported family conflicts and stress. These findings suggest that, as previously found among medical students (Magliano et al. 2013), future psychologists tend to associate the diagnostic label of schizophrenia with a biogenetic model, especially in the late stage of training. Furthermore, students who identified schizophrenia in the clinical description were more pessimistic about recovery, and perceived PWS as more dangerous/unpredictable, compared to students who did not. These results may partially explain the low percentage of people with this diagnosis being offered psychosocial treatments (Dixon et al. 2010; Haddock et al. 2014).

In line with findings from other studies, only $32.6 \%$ of psychology students completely agreed with the statement that "PWC can recover", although a further $62.9 \%$ partially agreed with this statement. It should be considered that the term "recovery" is problematic, as some will view it as being symptom-free while others will understand it to mean living a meaningful or contributing life ( $\mathrm{Ng}$ et al. 2011). It might be that students' belief that PWS will be completely symptom free may be more warranted than the alternative interpretation of recovery. However, any skepticism about the possibility of recovery is of concern since it may negatively influence the willingness of future psychologists to work with PWS, and it may discourage service users themselves in their efforts to be well again. It is particularly worrying that, as previously found in medical students (Magliano et al. 2012, 2013), psychology students also became more pessimistic about recovery, and gave more relevance to drugs and less relevance to psychological therapies at late stages of their training. In order to increase psychology students optimism about the possibility of recovering from schizophrenia, students should be exposed to scientific data showing that more than $50 \%$ of persons with schizophrenia recover from this disorder (Levine et al. 2011; Tibaldi and Govers 2012), and to testimonies of individuals who have recovered or are living successfully with symptoms of psychosis.

Despite a large sample size and a high response rate (100\%), this study - the first one carried out in Italy on future psychologists - has several weaknesses that should be considered when interpretating its results. The main limitations of this study include: a) the inclusion of students from only one psychology school located in southern Italy, a region where healthcare resources are poorer and public prejudices towards mentally ill persons are higher than in other areas of the country (as cited in Magliano et al. 2012); b) the focus only on beliefs regarding schizophrenia - one of the most stigmatised mental problem worldwide, together with alcohol and drug addictions 
(Henry et al. 2010; Pescosolido et al. 1999; 2010) - so its findings cannot be generalised to other mental disorders whose social acceptance by health professionals and the public is higher (Nordt et al. 2006; Schomerus et al. 2013); c) the fact that students' attendance to lessons is voluntary, therefore data cannot be generalised to not-attending students; d) the cross-sectional design that does not permit causal inferences regarding the effects of labelling and biogenetic explanations on stigmatizing attitudes. We plan to conduct further research on first-year students as a follow up to the current study; e) the failure to assess students' willingness to treat PWS; f) the poor reliability of the assessment questionnaire, whose psychometric properties we are now re-exploring, is a further significant limitation of this study.

Based on the findings of this study, we have scheduled several initiatives to sensitise students of our Psychology School to stigma and to introduce future psychologists to persons with schizophrenia. In particular, we regularly run seminars on "social dangerousness and incurability in schizophrenia" for psychology students in their last stage of training (Magliano et al. 2014). Further ongoing initiatives include the involvement of psychology students in participatory research addressing stigma-related issues in health and educational contexts, and peer-to-peer open seminars on "recovery from schizophrenia" held by psychology students themselves and based on testimonies. We hope that these initiatives will help to improve the attitudes of future psychologists toward PWS, and increase the probability that these people will receive the same psychological support as other citizens.

\section{APPEndix A}

Some people sometimes seem unable to distinguish between things that really happen and are experienced by other people, and things that happen only in their mind. Sometimes, these people believe or say things that seem bizarre or absurd to other people, or hear voices, smell things, or see images that other people do not. Sometimes, these people may have difficulty expressing their feelings or behaving appropriately (for instance, they may cry in response to a positive event, or may appear happy following an unpleasant one), or they may 
remain shut up in their house for a long time, or talk very little or not at all. They behave as if they lived in a world of their own, apparently without interest in anything or anybody. Sometimes they may have muddled thoughts, may invent odd or incomprehensible words, may lose the thread of the speech, or they may jump from one issue to another with no apparent reason.

\section{ACKNOWLEDGEMENTS}

The authors thank: a) the Professors of the Faculty of Psychology of the Second University of Naples who facilitated the conduction of the study:.; b) Dr. and Dr., psychologists, for their contribution in the collection and input of the data; c) the 566 participating students for their active involvement in the survey.

\section{CONFLICT OF INTEREST}

The authors declare that they have no conflicts of interests concerning this article. 


\section{REFERENCES}

- Angermeyer, M. C., Holzinger, A., Carta, M. G., \& Schomerus, G. (2011). Biogenetic explanations and public acceptance of mental illness: systematic review of population studies. British Journal of Psychiatry, 199, 367372.

- $\quad$ Ay, P., Save, D., \& Fidanoglu, O. (2006). Does stigma concerning mental disorders differ through medical education? A survey among medical students in Istanbul. Social Psychiatry and Psychiatric Epidemiology, $41,63-67$.

- $\quad$ Bennett, L., Thirlaway, K., \& Murray, A.J. (2008). The stigmatizing implications of presenting schizophrenia as a genetic disease. Journal of Genetic Counselling, 17, 550-559.

- Bosio, A.C., \& Lozza, E. Lo stato e le prospettive delle professioni psicologiche in Italia (The status and prospects of psychological professions in Italy) (2008). National Association of Psychologist. Retrived from www.psy.it/documents/Bosio_Lozza.pdf

- Buck, B., Romeo, K. H., Olbert, C. M., \& Penn, D. L. (2014). Self-reported comfort treating severe mental illnesses among pre-doctoral graduate students in clinical psychology. Journal of Mental Health, 23, 297-302.

- Consorzio Interuniversitario Alma Laurea (2014). Profilo dei laureati 2013 (Graduate students' profile). Retrived from: https://www.almalaurea.it/universita/profilo/profilo2013/volume

- Deacon, B. J. (2013). The biomedical model of mental disorder: a critical analysis of its validity, utility, and effects on psychotherapy research. Clinical Psychology Review, 33, 846-861.

- Dixon, L. B., Dickerson, F., Bellack, A. S., Bennett, M., Dickinson, D., Goldberg, R. W., ... Schizophrenia Patient Outcomes Research Team (PORT) (2010). The 2009 schizophrenia PORT psychosocial treatment recommendations and summary statements. Schizophrenia Bulletin, 36, 48-70.

- $\quad$ Pharoah, F., Mari, J., Rathbone, J., \& Wong, W. (2010). Family intervention for schizophrenia. The Cochrane Database of Systematic Reviews. 2010, 12, CD000088. doi: 10.1002/14651858.CD000088.pub2.

- Gaebel, W., Weinmann, S., Sartorius, N., Rutz, W., \& McIntyre, J.S. (2005). Schizophrenia practice guidelines: international survey and comparison. British Journal of Psychiatry, 187, 248-255.

- Haddock, G., Einsner, E., Boone, C., Davies, G., Coogan, C., \& Barrowclough, C. (2014). An investigation of the implementation of NICE-recommended CBT interventions for people with schizophrenia. Journal of Mental Health, 23, 162-165.

- Henry, J. D., von Hippel, C., \& Shapiro, L. (2010). Stereotype threat contributes to social difficulties in people with schizophrenia. British Journal of Clinical Psychology, 49, 31-41. 
- Hutton, P., Weinmann. S., Bola, J., \& Read, J. (2013) Antipsychotic drugs. In J. Read, \& J. Dillon (Eds.), Models of Madness (2nd edn) (pp. 105-124). London:Routledge.

- Kvaale, E. P., Haslam, N., \& Gottdiener, W. H. (2013). The "side effects" of medicalization: a meta-analytic review of how biogenetic explanations affect stigma. Clinical Psychology Review, 33, 782-794.

- Levine, S. Z., Lurie, I., Kohn, R., \& Levav, I. (2011). Trajectories of the course of schizophrenia: from progressive deterioration to amelioration over three decades. Schizophrenia Research, 126, 184-191.

- Lincoln, T. M., Arens, E., Berger, C., \& Rief, W. (2008). Can antistigma campaigns be improved? A test of the impact of biogenetic vs psychosocial causal explanations on implicit and explicit attitudes to schizophrenia. Schizophrenia Bulletin, 34, 984-994.

- Magliano, L., Fiorillo, A., De Rosa, C., Malangone, C., \& Maj, M. (2004). Beliefs about schizophrenia in Italy: a comparative nationwide survey of the general public, mental health professionals, and patients' relatives. Canadian Journal of Psychiatry, 49, 322-330.

- Magliano, L., Fiorillo, A., Malangone, C., De Rosa, C., \& Maj, M. (2006). Patient functioning and family burden in a controlled, real-world trial of family psychoeducation for schizophrenia. Psychiatric Services, 57, $1784-1791$

- Magliano, L., Read, J., Sagliocchi, A., Pantalano, M., D’Ambrosio, A., \& Oliviero, N. (2012). Differences in views of schizophrenia during medical education: a comparative study of 1 st versus 5 th-6th year Italian medical students. Social Psychiatry and Psychiatric Epidemiology, 48, 1647-1655.

- Magliano, L., Read, J., Sagliocchi, A., Patalano, M., \& Oliviero, N. (2013). Effect of diagnostic labeling and causal explanations on medical students' views about treatments for psychosis and the need to share information with service users. Psychiatry Research, 210, 402-407.

- Magliano, L., Read, J., Patalano, M., Sagliocchi, A., Oliviero, N., D’Ambrosio, A., ... Campitiello, F. (2014). "Social dangerousness and unpredictability in schizophrenia": results of an educational intervention for Medical and Psychology students. Psychiatry Research, 219, 457-463.

- Matheson, S.L., Shepherd, A.M., Pinchbeck, R.M., Laurens, K.R., \& Carr, V.J. (2013). Childhood adversity in schizophrenia: a systematic meta-analysis. Psychological Medicine, 43, 225-238.

- Morrison, A. (2013). Cognitive therapy for people experiencing psychosis. In J. Read, \& J. Dillon (Eds.), Models of Madness (2nd edn) (pp. 319-335). London:Routledge. 
- Morrison, A.P., Turkington, D., Pyle, M., Spencer, H., Brabban, A., Dunn, G., ... Hutton, P. (2014). Cognitive therapy for people with schizophrenia spectrum disorders not taking antipsychotic drugs: a single-blind randomised controlled trial. The Lancet, 383, 1395-1403.

- NICE (2014). Schizophrenia. National Institute of Clinical Excellence. CG178. Retrived from http://www.nice.org.uk/guidance/CG178

- Nordt, C., Rössler, W., \& Lauber, C. (2006). Attitudes of mental health professionals toward people with schizophrenia and major depression. Schizophrenia Bulletin, 32, 709-714.

- Ng, R. M., Pearson, V., Chen, E. E., \& Law, C. V. (2011). What does recovery from schizophrenia mean? Perceptions of medical students and trainee psychiatrists. International Journal of Social Psychiatry, 57, 248262.

- Pescosolido, B. A., Martin, J. K., Long, J. S., Medina, T. R., Phelan, J. C., \& Link, B. G. (2010). “A disease like any other?" A decade of change in public reactions to schizophrenia, depression, and alcohol dependence. American Journal of Psychiatry, 167, 1321-1330.

- Pescosolido, B.A., Monahan, J.K., Link, B.G., Stueve, A., \& Kikuzawa, S. (1999). The public's view of the competence, dangerousness, and need for legal coercion of persons with mental health problems. American Journal of Public Health, 89, 1339-1345.

- Prytys, M., Garety, P. A., Jolley, S., Onwumere, J., \& Craig, T. (2011). Implementing the NICE guideline for schizophrenia recommendations for psychological therapies: a qualitative analysis of the attitudes of CMHT staff. Clinical Psychology \& Psychotherapy, 18, 48-59.

- Read, J., \& Harré, N. (2001). The role of biological and genetic causal beliefs in the stigmatization of "mental patients”. Journal of Mental Health, 10, 223-235.

- Read, J., \& Law, A. (1999). The relationship of causal beliefs and contact with users of mental health services to attitudes to the "mentally ill". International Journal of Social Psychiatry, 45, 216-229.

- Read, J., Haslam, N., \& Magliano, L. (2013a). Prejudice, stigma and "schizophrenia": the role of bio-genetic ideology. In J. Read, \& J. Dillon (Eds.), Models of Madness (2nd edn) (pp. 157-177). London:Routledge.

- Read, J., Magliano, L., \& Beavan, V. (2013b). Public beliefs about the causes of "schizophrenia": bad things happen and can drive you crazy. In J. Read, \& J. Dillon (Eds.), Models of Madness (2nd edn) (pp. 143-156). London:Routledge. 
- Reavley, N. J., Mackinnon, A. J., Morgan, A. J., \& Jorm, A. F. (2014). Stigmatizing attitudes towards people with mental disorders: A comparison of Australian health professionals with the general community. Australian \& New Zealand Journal of Psychiatry, 48, 433-441.

- Sarin, F., Wallin, L., \& Widerlöv, B. (2011). Cognitive behavior therapy for schizophrenia: a meta-analytical review of randomized controlled trials. Nordic Journal of Psychiatry, 65, 162-174.

- Schomerus, G., Schwahn, C., Holzinger, A., Corrigan, P.W., Grabe, H.J., ...\& Angermeyer, M.C. (2012). Evolution of public attitudes about mental illness. Acta Psychiatrica Scandinavica 125, 440-452.

- Schomerus, G., Matschinger, H., \& Angermeyer, M. C. (2013). Continuum beliefs and stigmatizing attitudes towards persons with schizophrenia, depression and alcohol dependence. Psychiatry Research, 209, 665-669.

- Seikkula J, Olson ME (2003). The open dialogue approach to acute psychosis: its poetics and micropolitics. Family Process, 42, 403-418.

- Semisa, D., Lasalvia, A., Miceli, M., Dall'Agnola, R. B., Pucci, C., Bissoli, S., ... Gruppo SIEP-DIRECT'S (2008). The acceptability of the NICE recommendations for schizophrenia in the Italian Departments of Mental Health. The SIEP-DIRECT'S Project on the discrepancy between routine practice and evidence. Epidemiologia e Psichiatria Sociale, 17, 291-304.

- Servais, L. M., \& Saunders, S. M. (2007). Clinical psychologists' perceptions of persons with mental illness. Professional Psychology, 38, 214-219.

- Speerforck, S., Schomerus, G., Pruess, S., \& Angermeyer, M. C. (2014). Different biogenetic causal explanations and attitudes towards persons with major depression, schizophrenia and alcohol dependence: Is the concept of a chemical imbalance beneficial? Journal of Affective Disorders, 168, 224-228.

- Summer, A. \& Rosenbaum, B. Psychodynamic psychotherapy for psychosis. In J. Read, \& J. Dillon (Eds.), Models of Madness (2nd edn) (pp. 336-344). London:Routledge.

- Tibaldi, G., \& Govers, L. (2012). Evidence-based hope for recovery from "schizophrenia": A common objective for all stakeholders in the mental health field. Psychosis, 4, 105-114. 


\begin{tabular}{|c|c|c|c|c|c|c|}
\hline \multirow[t]{3}{*}{ Causes* } & \multirow{2}{*}{\multicolumn{2}{|c|}{$\begin{array}{l}\text { Total sample } \\
\qquad(\mathrm{N}=566)\end{array}$}} & \multicolumn{4}{|c|}{ Schizophrenia label } \\
\hline & & & \multicolumn{2}{|c|}{ Yes $(N=357)$} & \multicolumn{2}{|c|}{ No (209) } \\
\hline & $\mathbf{N}$ & $\%$ & $\mathbf{N}$ & $\%$ & $\mathbf{N}$ & $\%$ \\
\hline Psychological traumas & 386 & 68.2 & 229 & 64.1 & 157 & 75.1 \\
\hline Heredity ${ }^{a}$ & 304 & 53.7 & 262 & 73.4 & 42 & 20.1 \\
\hline Stress ${ }^{a}$ & 268 & 47.3 & 126 & 35.3 & 142 & 67.9 \\
\hline Misuse of street drugs & 223 & 39.4 & 152 & 42.6 & 71 & 34.0 \\
\hline Family conflicts ${ }^{\text {a }}$ & 215 & 38.0 & 106 & 29.7 & 109 & 52.2 \\
\hline Chemical imbalance $^{\mathrm{a}}$ & 194 & 34.3 & 155 & 43.4 & 39 & 18.7 \\
\hline Misuse of alcohol & 146 & 25.8 & 103 & 28.9 & 43 & 20.6 \\
\hline Incorrect therapy & 113 & 20.0 & 70 & 19.6 & 43 & 20.6 \\
\hline Disillusionment in love ${ }^{\text {a }}$ & 106 & 18.7 & 39 & 10.9 & 67 & 32.1 \\
\hline Illness in pregnancy or childhood & 82 & 14.5 & 55 & 15.4 & 27 & 12.9 \\
\hline Physical illness ${ }^{a}$ & 65 & 11.5 & 27 & 7.6 & 38 & 18.2 \\
\hline Frequenting bad company ${ }^{a}$ & 26 & 4.6 & 4 & 1.1 & 22 & 10.5 \\
\hline
\end{tabular}




\begin{tabular}{|c|c|c|c|c|c|c|c|}
\hline \multirow[t]{3}{*}{ Items } & & \multirow{2}{*}{\multicolumn{2}{|c|}{$\begin{array}{c}\text { Total sample } \\
\qquad(\mathrm{N}=566)\end{array}$}} & \multicolumn{4}{|c|}{ Schizophrenia label } \\
\hline & & & & \multicolumn{2}{|c|}{ Yes $(\mathrm{N}=357)$} & \multicolumn{2}{|c|}{ No (209) } \\
\hline & & $\mathbf{N}$ & $\%$ & $\mathbf{N}$ & $\%$ & $\mathbf{N}$ & $\%$ \\
\hline \multirow{3}{*}{$\begin{array}{l}\text { Drugs are useful in } \\
\text { the treatment of *a }\end{array}$} & Completely true & 124 & 23.7 & 106 & 31.3 & 18 & 9.7 \\
\hline & Partially true & 362 & 69.1 & 225 & 64.4 & 137 & 74.1 \\
\hline & Not true & 38 & 7.2 & 8 & 2.3 & 30 & 16.2 \\
\hline Psychological & Completely true & 338 & 60.8 & 191 & 54.4 & 147 & 71.7 \\
\hline interventions are & Partially true & 213 & 38.3 & 156 & 44.4 & 57 & 27.8 \\
\hline useful in the & Not true & 5 & 0.9 & 4 & 1.1 & 1 & 0.5 \\
\hline \multirow[t]{3}{*}{${ }^{*}$ can recover ${ }^{\mathrm{a}}$} & Completely true & 160 & 32.6 & 69 & 22.9 & 91 & 47.9 \\
\hline & Partially true & 309 & 62.9 & 217 & 72.1 & 92 & 48.4 \\
\hline & Not true & 22 & 4.5 & 15 & 5.0 & 7 & 3.7 \\
\hline$*$ are dangerous to & Completely true & 59 & 11.7 & 46 & 14.2 & 13 & 7.2 \\
\hline others $^{\mathrm{a}}$ & Partially true & 417 & 82.7 & 269 & 83.3 & 148 & 81.8 \\
\hline & Not true & 28 & 5.6 & 8 & 2.5 & 20 & 11.0 \\
\hline \multirow{3}{*}{ * are unpredictable ${ }^{a}$} & Completely true & 209 & 41.5 & 151 & 46.0 & 58 & 33.0 \\
\hline & Partially true & 265 & 52.6 & 166 & 50.6 & 99 & 56.2 \\
\hline & Not true & 30 & 5.9 & 11 & 3.4 & 19 & 10.8 \\
\hline
\end{tabular}

